\title{
Effect of Copper and Molybdenum on Microstructure and Fatigue Properties of Nodular Cast Irons
}

\author{
Alan Vaško, Juraj Belan, Eva Tillová \\ Department of Materials Engineering, Faculty of Mechanical Engineering, University of Žilina, Univerzitná 8215/1, \\ 01026 Žilina, Slovakia. e-mail: alan.vasko@fstroj.uniza.sk
}

\begin{abstract}
The aim of this paper is to compare the microstructure, mechanical and fatigue properties of three types of the nodular cast irons - unalloyed nodular cast iron, nodular cast iron alloyed by Si and Mo and nodular cast iron alloyed by $\mathrm{Si}$ and $\mathrm{Cu}$. For all the types, microstructure, mechanical properties and fatigue properties were investigated. Microstructure of the specimens was evaluated according to STN EN ISO 945 and by automatic image analysis. The image analysis system NIS Elements, interfaced with the light microscope, was used for the evaluation of the shape factor, equivalent diameter of graphite, count of graphitic nodules and content of ferrite. The mechanical properties were evaluated by the tensile test, impact bending test and Brinell hardness test. Fatigue tests were realised at sinusoidal cyclic push-pull loading (stress ratio $R=-1)$ at ambient temperature $(T=20 \pm$ $5^{\circ} \mathrm{C}$ ). They were carried out in the high cycle fatigue region (from $10^{5}$ to $10^{7}$ cycles) at frequency $\mathrm{f} \approx 75 \mathrm{~Hz}$ using the fatigue experimental machine Zwick/Roell Amsler 150HFP 5100. The relationship between the amplitude of stress $\sigma_{\mathrm{a}}$ and the number of cycles to failure $\mathrm{N}$, as well as the fatigue strengths, were determined.
\end{abstract}

Keywords: SiMo-nodular cast iron, $\mathrm{SiCu}$-nodular cast iron, Microstructure, Fatigue properties

\section{Introduction}

The nodular cast iron, also known as ductile cast iron or spheroidal cast iron, is a type of graphitic cast iron, which contains graphite in the form of nodules. The spheroidal shape of graphite does not cause such a high concentration of stress as a lamellar graphite. Therefore, the nodular cast iron has higher tensile strength and plasticity, as well as higher fatigue strength than the lamellar cast iron. The nodular cast iron is a group of cast structural materials with a wide application in engineering practice, especially in the automotive industry $[1,2]$.

The nodular cast irons alloyed by Si and Mo are often used for high temperature applications, for example castings of the exhaust pipes of the combustion engine or turbo charger housings. Those castings are able to perform many thousands of cycles that can range from below freezing temperatures to those higher than $750{ }^{\circ} \mathrm{C}$. The SiMo-nodular cast iron usually has a ferritic matrix, but may also contain pearlite and carbides. Increasing content of silicon promotes the stability of the microstructure and properties at low and high temperature by forming a highly ferritic matrix structure and by raising the austenite transformation temperature. Increasing concentration of silicon increases the yield strength, but lowers toughness and elongation. Therefore, the material can be very brittle at room temperature. Molybdenum partially segregates during the solidification and forms a carbidic phase on grain boundaries. This carbidic network improves the dimensional stability, increases the tensile strength, creep resistance and corrosion resistance but reduces plastic properties [3-6].

The nodular cast irons alloyed by $\mathrm{Si}$ and $\mathrm{Cu}$ are used in various components of tribo-technical units. The $\mathrm{SiCu}$ nodular cast iron is characterized by a high content of pearlite in a matrix and the presence of inclusions of a structurally free copper-bearing phase. Copper is a graph- itizing element and it increases the degree of pearlitization of the structure. By hardening ferrite and pearlite, copper increases strength and hardness of nodular cast iron. It also rises the corrosion resistance, improves wear resistance and decreases friction coefficient of nodular cast irons [7-9].

The aim of this study was to compare the microstructure, mechanical and fatigue properties of three types of the nodular cast irons described above, that is the nonalloyed nodular cast iron, SiMo-nodular cast iron and $\mathrm{SiCu}$-nodular cast iron.

\section{Experimental material and methods}

For experiments, three types of the nodular cast irons were used:

- unalloyed nodular cast iron, which corresponds to EN-GJS-HB185;

- SiMo-nodular cast iron with content of silicon $4 \%$ and content of molybdenum $1 \%$, which corresponds to EN-GJS-SiMo4-1;

- SiCu-nodular cast iron with content of silicon $4 \%$ and content of copper $1.5 \%$, which corresponds to EN-GJS-SiCu4-1.5.

Melting was realised in electric induction furnaces at the Department of Technological Engineering at University of Žilina, Slovak Republic and at the Department of Foundry Engineering at Brno University of Technology, Czech Republic.

Charge composition of the melts is given in Tab. 1 . The basic charge of the melts was made up of $60 \%$ of steel and $40 \%$ of pig iron with additives for regulation of the chemical composition, i.e. carburizer, ferrosilicon FeSi75, ferromolybdenum FeMo65 or copper. The content of those additives was chosen to achieve required 
chemical composition of the melts and eutectic degree approximately $\mathrm{S}_{\mathrm{C}} \approx 1.0$. For modification the $\mathrm{FeSiMg} 7$ modifier was used and for inoculation the FeSi75 inoculant was used.

Tab. 1 Charge composition of the melts

\begin{tabular}{|c|c|c|c|c|c|c|c|c|c|}
\hline \multirow{2}{*}{ Melt } & \multicolumn{7}{|c|}{ Charging raw materials (kg) } & \multicolumn{4}{|c|}{} \\
\cline { 2 - 11 } & steel & pig iron & carburizer & FeSi75 & FeMo65 & Cu & $\begin{array}{r}\text { modifier } \\
\text { FeSiMg7 }\end{array}$ & $\begin{array}{c}\text { inoculant } \\
\text { FeSi75 }\end{array}$ & $\begin{array}{c}\text { cover } \\
\text { sheet }\end{array}$ \\
\hline unalloyed GJS & 18 & 12 & 0.65 & 0.75 & & & 0.5 & 0.2 & 2 \\
\hline GJS-SiMo & 27 & 20 & 1.2 & 2.1 & 1.1 & & 0.5 & 0.4 & 3 \\
\hline GJS-SiCu & 27 & 20 & 1.1 & 2.1 & & 0.7 & 0.5 & 0.4 & 3 \\
\hline
\end{tabular}

All three types of nodular cast irons were cast into sand molds in the shape of the Y blocks (Fig. 1). The resultant chemical composition of the melts is given in Tab. 2. Test specimens for microstructural analysis, mechanical tests and fatigue tests were machined from the $\mathrm{Y}$ blocks.



Fig. 1 Shape and parameters of the Y block

Tab. 2 Chemical composition of the melts

\begin{tabular}{|c|c|c|c|c|c|c|c|c|c|c|}
\hline \multirow{2}{*}{$\begin{array}{c}\text { Melt } \\
\end{array}$} & \multicolumn{9}{|c|}{ Content of chemical elements (weight \%) } \\
\cline { 2 - 13 } & $\mathrm{C}$ & $\mathrm{Si}$ & $\mathrm{Mn}$ & $\mathrm{P}$ & $\mathrm{S}$ & $\mathrm{Cr}$ & $\mathrm{Mo}$ & $\mathrm{Cu}$ & $\mathrm{Ni}$ & $\mathrm{S}_{\mathrm{C}}$ \\
\hline unalloyed GJS & 3.51 & 3.59 & 0.32 & 0.07 & 0.028 & 0.09 & 0.01 & 0.01 & 0.05 & 1.10 \\
& & & & & & & & & & \\
\hline GJS-SiMo & 3.021 & 4.094 & 0.376 & 0.026 & 0.032 & 0.084 & 0.938 & 0.115 & 0.059 & 1.002 \\
\hline GJS-SiCu & 3.281 & 4.156 & 0.363 & 0.028 & 0.037 & 0.072 & 0.009 & 1.394 & 0.055 & 1.096 \\
\hline
\end{tabular}

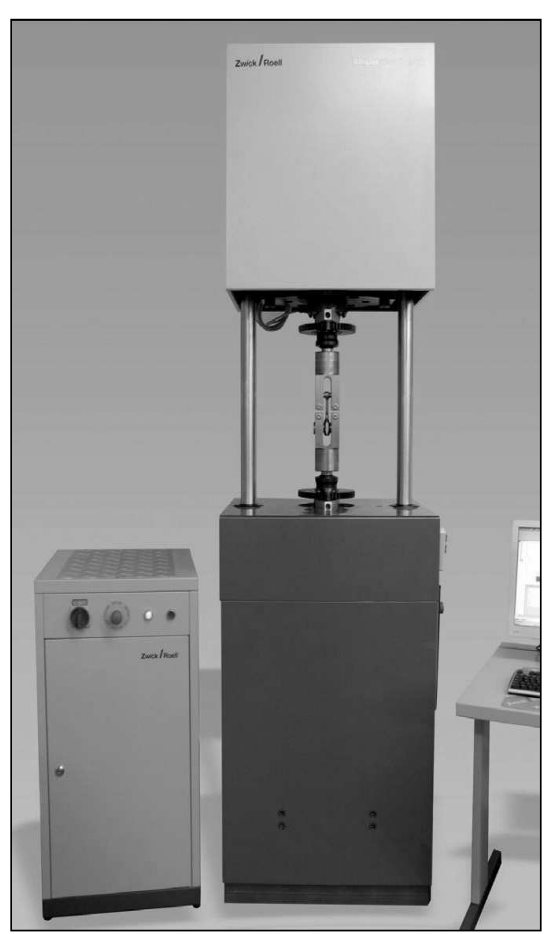

a) fatigue experimental machine Zwick/Roell Amsler 150HFP 5100

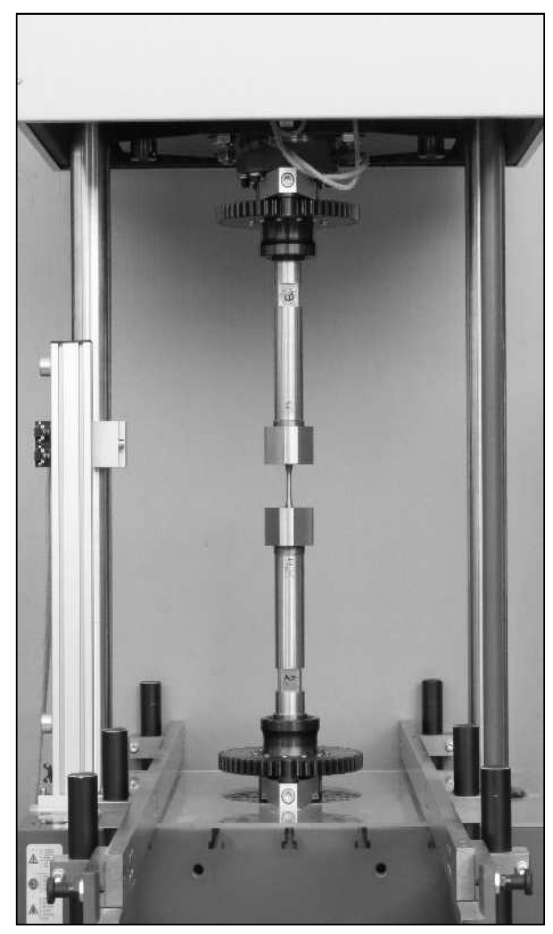

b) detail of fatigue testing

Fig. 2 Experimental machine and test specimen used for fatigue tests 
The metallographic analysis of the specimens was done by the light metallographic microscope Neophot 32 . The specimens for metallographic analysis were prepared by usual metallographic procedure. Microstructure of the specimens was evaluated according to STN EN ISO 945 (STN 42 0461) and by automatic image analysis (using the NIS Elements software) [10]. The subject of image analysis was evaluation of the shape factor, equivalent diameter of graphite, count of graphitic nodules per unit area and content of ferrite.

The tensile test was performed according to STN EN ISO 6892-1 by means of the testing equipment Instron 5985 with a loading range $\mathrm{F}=0$ to $50 \mathrm{kN}$. For the tensile test, cylindrical test specimens with diameter $\mathrm{d}_{0}=10 \mathrm{~mm}$ and measured length $1_{0}=50 \mathrm{~mm}$ were used. The impact bending test was executed according to STN EN ISO 1481 by means of the Charpy hammer PSW 300 with a nominal energy of $300 \mathrm{~J}$. For the impact bending test, test specimens of square cross-section with a width $\mathrm{a}_{0}=10$ $\mathrm{mm}$ and length $1_{0}=55 \mathrm{~mm}$ were used. The Brinell hardness test was done according to STN EN ISO 6506-1 by means of the testing equipment CV-3000 LDB with a hard-metal ball of diameter $\mathrm{D}=10 \mathrm{~mm}$ forced into specimens under the load $\mathrm{F}=29430 \mathrm{~N}(3000 \mathrm{kp})$. The values of mechanical properties were determined as an average of three measurements.

The fatigue tests were carried out according to STN 420362 at low frequency sinusoidal cyclic push-pull loading (stress ratio $\mathrm{R}=-1$ ) at ambient temperature $(\mathrm{T}=$ $20 \pm 5^{\circ} \mathrm{C}$ ). They were realised in the high cycle fatigue region (from $10^{5}$ to $10^{7}$ cycles) at frequency $\mathrm{f} \approx 75 \mathrm{~Hz}$ using the fatigue experimental machine Zwick/Roell Amsler 150HFP 5100 (Fig. 2 a,b). For the fatigue tests, specimens of circular cross-section with a diameter $\mathrm{d}_{0}=$ $8 \mathrm{~mm}$ were used. Shape and parameters of the specimens for the fatigue tests are shown in Fig. 2c. 15 specimens from all the melts were used to determine the fatigue characteristics (relationship between the amplitude of stress $\sigma_{\mathrm{a}}$ and number of cycles to failure $\mathrm{N}_{\mathrm{f}}$, as well as the fatigue strength) [11-14].

\section{Experimental results and discussion}

From a microstructural point of view, the specimen of unalloyed GJS is a ferrite-pearlitic nodular cast iron (Fig. $3 \mathrm{a}$ ), the specimen of GJS-SiMo is a ferrite-pearlitic nodular cast iron (Fig. 3b) and the specimen of GJS-SiCu is a pearlite-ferritic nodular cast iron (Fig. 3c). Evaluation of the microstructure of the specimens by STN EN ISO 945 (STN 42 0461) and by image analysis (shape factor, equivalent diameter of graphite, count of graphitic nodules per unit area and content of ferrite) are presented in Tab. 3.

The specimen of unalloyed GJS has the highest content of ferrite from all the specimens. Content of ferrite in the specimen of GJS-SiCu is lower than in the specimen of GJS-SiMo because of pearlitizing effect of copper. Graphite occurs predominantly in a perfectly-nodular shape in all the specimens. Size of graphite in the specimen of GJS-SiCu is smaller than in the specimen of GJSSiMo, but an average count of graphitic nodules per unit area in the specimen of GJS-SiCu is higher than in the specimen of GJS-SiMo. Size of graphite and count of graphitic nodules in the specimen of unalloyed GJS are between values in the specimens of GJS-SiCu and GJSSiMo. Different microstructure is caused by different charge composition.

Tab. 3 Microstructure of the specimens

\begin{tabular}{|c|c|c|c|c|c|}
\hline Melt & $\begin{array}{c}\text { Microstructure } \\
\text { (according to STN EN ISO 945) }\end{array}$ & Shape factor & $\begin{array}{c}\text { Equivalent di- } \\
\text { ameter of } \\
\text { graphite }(\mu \mathrm{m})\end{array}$ & $\begin{array}{c}\text { Count of graphitic } \\
\text { nodules }\left(\mathrm{mm}^{-2}\right)\end{array}$ & $\begin{array}{c}\text { Content of } \\
\text { ferrite }(\%)\end{array}$ \\
\hline unalloyed GJS & $90 \% \mathrm{VI6} / 7+10 \% \mathrm{~V} 6-\mathrm{Fe} 80$ & 0.82 & 29.5 & 151.0 & 72.9 \\
\hline GJS-SiMo & $90 \% \mathrm{VI} 6+10 \% \mathrm{~V} 6-\mathrm{Fe} 80$ & 0.88 & 31.2 & 122.8 & 59.4 \\
\hline GJS-SiCu & $90 \% \mathrm{VI} 6 / 7+10 \% \mathrm{~V} 6-\mathrm{Fe} 15$ & 0.84 & 24.3 & 172.4 & 19.7 \\
\hline
\end{tabular}

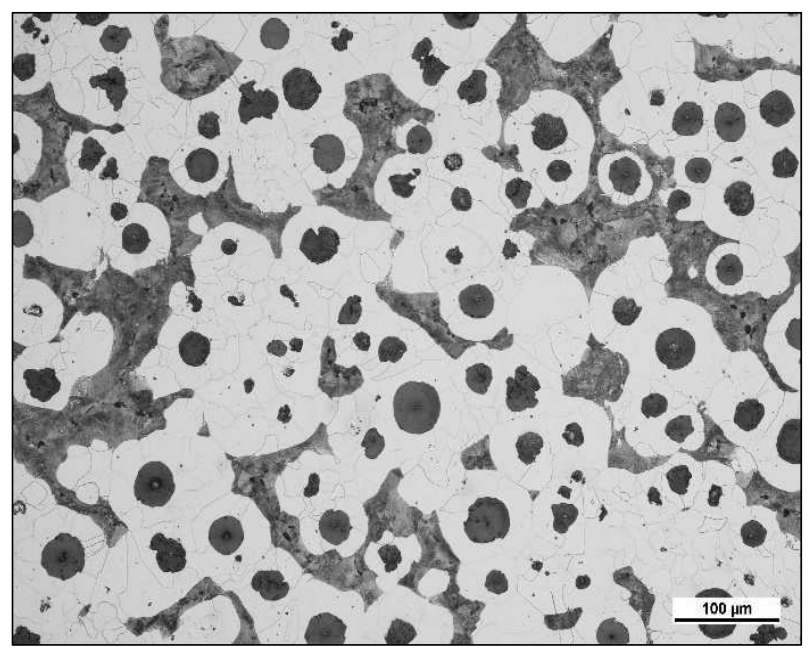

a) unalloyed GJS-ferrite-pearlitic nodular cast iron

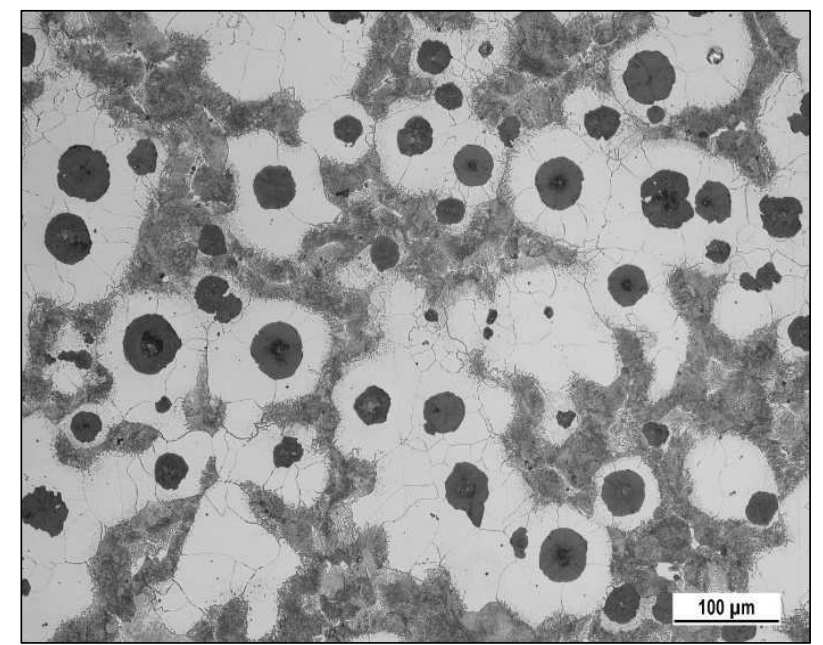

b) GJS-SiMo - ferrite-pearlitic nodular cast iron 


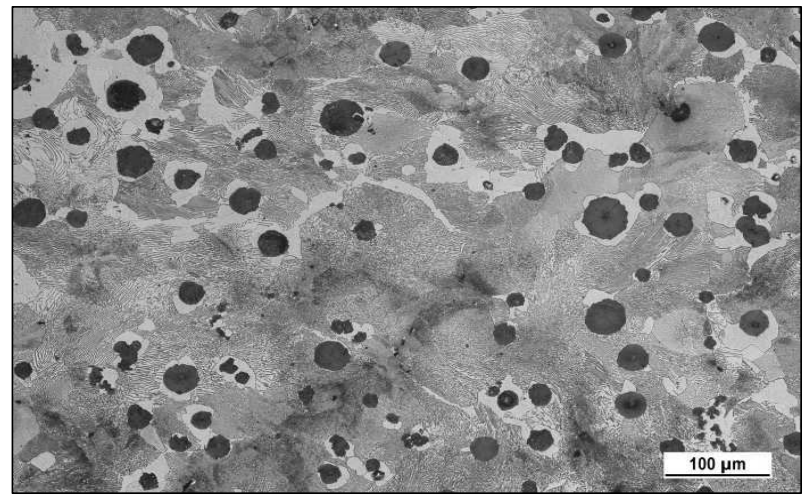

c) GJS-SiCu-pearlite-ferritic nodular cast iron

Fig. 3 Microstructure of the specimens, etched by $1 \%$ Nital

Results of mechanical tests (tensile test, impact bending test and Brinell hardness test) are given in Tab. 4.
The specimen of GJS-SiCu has higher yield strength $\mathrm{R}_{\mathrm{p} 0,2}$, tensile strength $\mathrm{R}_{\mathrm{m}}$ and Brinell hardness HBW, but lower elongation $\mathrm{A}$ and absorbed energy $\mathrm{K} 0$ than the specimen of GJS-SiMo. The specimen of unalloyed GJS has lower tensile strength and hardness, but better plasticity than the specimens of GJS-SiCu and GJS-SiMo. That is related to the microstructure of the specimens, especially to the character of matrix (content of ferrite and pearlite) and also to the size of graphite and count of graphitic nodules.

For the fatigue tests, 15 specimens from all the melts were used to obtain Wöhler fatigue curves $\sigma_{a}=f(N)$ and determine the fatigue strength $\sigma_{\mathrm{c}}$ for $\mathrm{N}=10^{7}$ cycles. Results of fatigue tests (relationship between stress amplitude $\sigma_{\mathrm{a}}$ and number of cycles to failure $\mathrm{N}_{\mathrm{f}}$ ), obtained at low frequency cyclic loading ( $\mathrm{f} \approx 75 \mathrm{~Hz}$ ), are shown in Fig. 4 . The number of cycles to failure increases with a decreasing stress amplitude.

Tab. 4 Mechanical and fatigue properties of the specimens

\begin{tabular}{|c|c|c|c|c|c|c|}
\hline Melt & $\mathrm{R}_{\mathrm{p} 0,2}(\mathrm{MPa})$ & $\mathrm{R}_{\mathrm{m}}(\mathrm{MPa})$ & $\mathrm{A}(\%)$ & $\mathrm{K} 0(\mathrm{~J})$ & $\begin{array}{c}\mathrm{HBW} \\
10 / 3000 / 10\end{array}$ & $\sigma_{\mathrm{c}}(\mathrm{MPa})$ \\
\hline unalloyed GJS & & 462.6 & 2.7 & 24.0 & 197.0 & 230 \\
\hline GJS-SiMo & 515.3 & 573.9 & 1.4 & 11.3 & 213.7 & 210 \\
\hline GJS-SiCu & 631.1 & 652.7 & 0.7 & 8.0 & 247.3 & 270 \\
\hline
\end{tabular}

The values of fatigue strength $\sigma_{c}$, determined for $\mathrm{N}=$ $10^{7}$ cycles, are given in Tab. 4 . The specimen of GJS$\mathrm{SiCu}$ has higher tensile strength $\mathrm{R}_{\mathrm{m}}$, as well as fatigue strength $\sigma_{c}$ than the specimen of GJS-SiMo. These results of experiments have shown that the fatigue strength of nodular cast irons increases with an increasing tensile strength what corresponds to previous study [15]. In comparison to non-alloyed nodular cast iron, the specimen of GJS-SiCu has higher fatigue strength than the specimen of unalloyed GJS, but the specimen of GJS-SiMo has lower fatigue strength than the specimen of unalloyed GJS, although it has the lowest tensile strength.

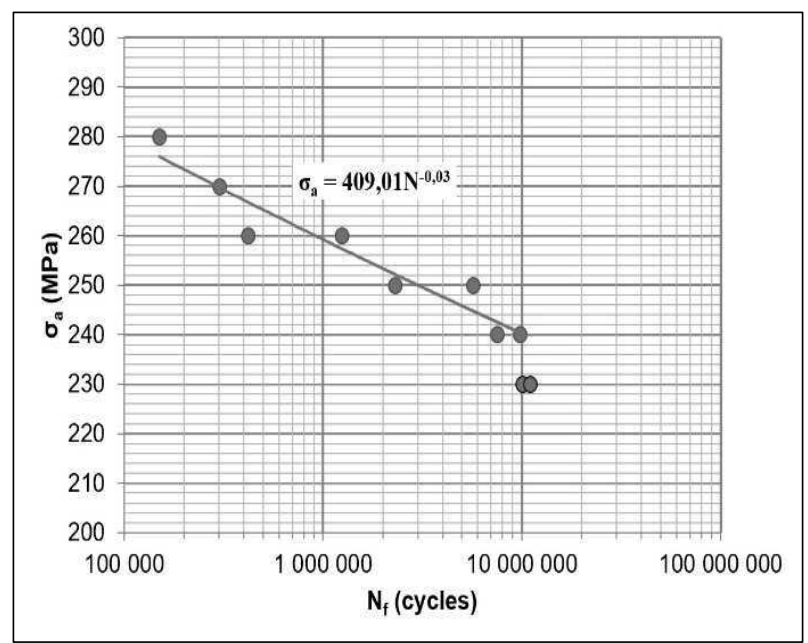

a) unalloyed GJS, $\sigma_{c}=230 \mathrm{MPa}$

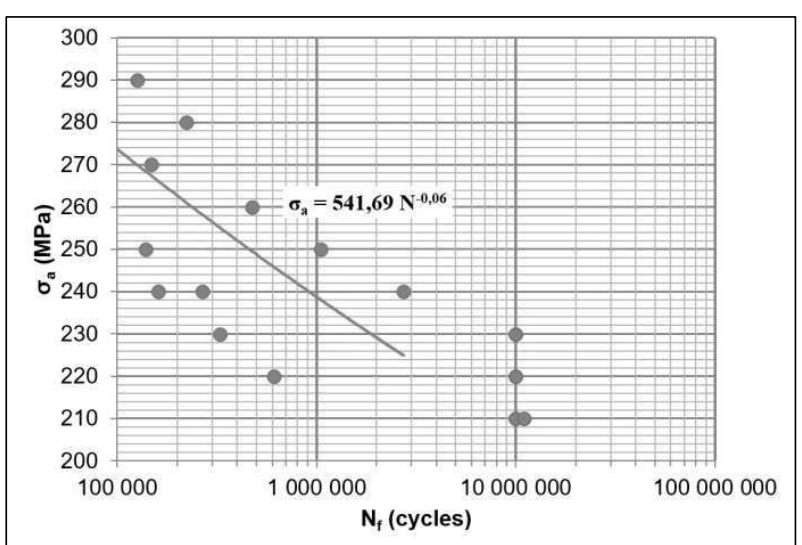

b) GJS-SiMo, $\sigma_{c}=210 \mathrm{MPa}$



c) GJS-SiCu, $\sigma_{c}=270 \mathrm{MPa}$

Fig. 4 Wöhler fatigue curves $\sigma_{a}=f(N)$ 


\section{Conclusions}

The results of experiments show that the charge composition influences the microstructure, mechanical as well as fatigue properties of the nodular cast iron. The experimental results can be summarized to the following points:

- Copper has a pearlitizing and graphitizing effect, therefore the specimen of GJS-SiCu has lower content of ferrite, smaller size of graphite and higher count of graphitic nodules per unit area than the specimens of GJS-SiMo and unalloyed GJS.

- These structural changes have brought about a change of mechanical properties, which depend especially on the character of matrix (content of ferrite), as well as on size of graphite and count of graphitic nodules. Therefore, the specimen of GJS-SiCu has higher yield strength, tensile strength and hardness, but lower elongation and absorbed energy than the specimens of GJSSiMo and unalloyed GJS.

- The fatigue strength of nodular cast irons is related to the tensile strength. The specimen of GJS-SiCu has higher tensile strength, therefore it also has higher fatigue strength than the specimens of GJS-SiMo and unalloyed GJS. The specimen of GJS-SiMo has higher tensile strength than the specimen of unalloyed GJS but a slightly lower fatigue strength. The effect of molybdenum on fatigue properties is manifested especially at higher temperatures.

\section{Acknowledgement}

The research has been supported by the Scientific Grant Agency of Ministry of Education, Science, Research and Sport of Slovak Republic, grant project VEGA No. 1/0533/15 and by the Culture and Educational Grant Agency of Ministry of Education, Science, Research and Sport of Slovak Republic, grant project KEGA No. $049 \check{Z} U-4 / 2017$.

\section{References}

[1] BOKŮVKA, O., NICOLETTO, G., GUAGLIANO, M., KUNZ, L., PALČEK, P., NOVÝ, F., CHALUPOVÁ, M. (2014). Fatigue of materials at low and high frequency loading, EDIS, Žilina.

[2] ULEWICZ, R. (2014). Practical application of quality tools in the cast iron foundry. In: Manufacturing Technology, Vol. 14, No. 1, pp. 104-111.
[3] ROUČKA, J., ABRAMOVÁ, E., KAŇA, V. (2018). Properties of type SiMo ductile irons at high temperatures. In: Archives of Metallurgy and Materials, Vol. 63, No. 2, pp. 601-607.

[4] STAWARZ, M. (2017). SiMo ductile iron crystallization process. In: Archives of Foundry Engineering, Vol. 17, No. 1, pp. 147-152.

[5] MATteis, P., SCAVINO, G., CASTEllo, A., FIRRAO, D. (2014). High temperature fatigue properties of a Si-Mo ductile cast iron. In: Procedia Materials Science, No. 3, pp. 2154-2159.

[6] ÅBERG, L. M., HARTUNG, C. (2012). Solidification of SiMo nodular cast iron for high temperature applications. In: Transactions of the Indian Institute of Metals, Vol. 65, No. 6, pp. 633-636.

[7] SIL'MAN, G. I., KAMYNIN, V. V., TARASOV, A. A. (2003). Effect of copper on structure formation in cast iron. In: Metal Science and Heat Treatment, Vol. 45, No. 7-8, pp. 254-258.

[8] GUMIENNY, G., KACPRZYK, B., GAWROŃSKI, J. (2017). Effect of copper on the crystallization process, microstructure and selected properties of CGI. In: Archives of Foundry Engineering, Vol. 17, No. 1, pp. 51-56.

[9] RAZUMAKOV, A. A., STEPANOVA, N. V., BATAEV, I. A., LENIVTSEVA, O. G., RIAPOLOVA I. I., EMURLAEV, K. I. (2016). The structure and properties of cast iron alloyed with copper. In: Materials Science and Engineering, Vol. 124, Article number 012136.

[10] SKOČOVSKÝ, P., VAŠKO, A. (2007). Quantitative evaluation of structure of cast irons, EDIS, Žilina.

[11] TRŠKO, L., NOVÝ, F., BOKU゚VKA, O., JAMBOR, M. (2018). Ultrasonic fatigue testing in the tension-compression mode. In: Journal of $\mathrm{Vi}$ sualized Experiments, No. 133, Article number e57007.

[12] UHRÍČIK, M., PALČEK, P., CHALUPOVÁ, M., ORŠULOVÁ, T. (2017). The structure of the aluminium alloy and its influence on the fatigue properties. In: Manufacturing Technology, Vol. 17, No. 5, pp. 863-869.

[13] KOPAS, P., JAKUBOVIČOVÁ, L., VAŠKO, M., HANDRIK, M. (2015). Fatigue resistance of reinforcing steel bars. In: Procedia Engineering, Vol. 136, pp. 193-197.

[14] POBOČÍKOVÁ, I., SEDLIAČKOVÁ, Z. (2005). Linear regression by MATLAB. In: Proceedings of Aplimat 2005, p. 351-356. STU Bratislava.

[15] VAŠKO, A. (2017). Fatigue properties of nodular cast iron at low frequency cyclic loading. In: $A r$ chives of Metallurgy and Materials, Vol. 62, No. 4, pp. 2205-2210. 